\title{
UNIVERSIDAD, INTELIGENCIA E IDEOLOGIA
}

\section{En torno a algunas ideas de José Medina Echavarría*}

\author{
Jorge Graciarena*
}

Si la universidad ha de ser la "más clara conciencia de la época" — como en uno de sus trabajos acotaba Medina Echavarría ${ }^{28}$ - tendrá por fuerza que ser ella misma una parte de la inteligencia y compartir sus responsabilidades. Su misión será por consiguiente la de orientar en situaciones de crisis y comprometerse con la búsqueda de salidas que permitan superarlas. "La más alta entre 'peculiares' creaciones de occidente, la universidad, nació en cuanto 'institucionalización de la inteligencia”', (154) añadía Medina poniendo el acento en la estrecha vinculación existente —desde sus orígenes mismosentre la universidad occidental y la inteligencia. Es precisamente esta particular relación - su índole y variaciones históricas - lo que se explora someramente en las notas que siguen, que no tienen otra pretensión que la de aportar elementos para una discusión.

Si se acepta en algún grado la idea de Toynbee — tan gráficamente expresada con sus metáforas- de que los momentos de cambio son como "ríos revueltos" en que el proceso histórico va dejando "cabos sueltos", y que para que haya una "salida" éstos deben ser anudados en torno a algún nuevo principio organizador capaz de servir de núcleo y cemento de una nueva fase histórica.

Se advierte que en ella está implícita la importancia de la función intelectual en la resolución de estas crisis objetivas. Con Medina se podría agregar que la búsqueda de una salida constituye la responsabilidad primigenia de la inteligencia como razón histórica.

Lo que aquí se denomina función intelectual, que es ni más ni menos que la actividad de la inteligencia, comprende una gama muy vasta de acciones que pueden ser ejercidas por muy diversos agentes sociales de acuerdo con las circunstancias en que aquélla se produce y la índole que asuma como fuerza social ${ }^{29}$. Sea lo que fuere, cabe señalar sin embargo que en ja cultura occidental esta función intelectual ha tendido a mantenerse concentrada alrededor de algunas instituciones, grupos e individuos que la han ejercido con más intensidad, profundidad y sentido de orientación que otros actores sociales. Dicho esto sin perjuicio de la contribución de todos -aunque con sentidos siempre

\footnotetext{
* Trabajo presentado en homenaje a José Medina Echavarría en Madrid.

** Sociólogo argentino. Antiguo profesor del Departamento de Sociología de la Universidad Nacional. Exdirector de la oficina de desarrollo social de la CEPAL. Autor de numerosos trabajos de sociología política y de sociología de la educación.

${ }^{28}$ Salvo que se indique otra cosa todas las referencias que siguen a trabajos de José Medina Echevarría proceden de su libro Filosofía, educación y desarrollo (México, Siglo XXI, 1967).

29 "Los intelectuales se ocupan de ideas, de reminiscencias del pasado, de definiciones del presente y de imágenes de posibles futuros. Por intelectuales entiendo científicos y artistas, sacerdotes y catedráticos; comprendo a aquéllos que representan el intelecto humano; a aquéllos que forman parte del gran discurso de la razón y la indagación, de la sensibilidad e imaginación que en Occidente comenzó en Jerusalén, Atenas y Roma, y ha venido desarrollándose en forma intermitente desde entonces. Son la memoria organizada de la humanidad, tal aparato cultural ha sido creado y es sostenido por ellos. Si escriben, pintan y hablan, si crean y distribuyen imágenes e ideas, su labor es públicamente provechosa... Justifican ideas de autoridad o las critican... Mientras que sean intelectuales, tienen que razonar e investigar, y, con su pasión por saber, deben encarar las situaciones de los hombres en todas las partes. Esperar esto de sí mismo es rasgo distintivo del intelectual como prototipo de criatura social y moral”. O. WRIGHT MILLS, Las causas de la tercera guerra mundial (Buenos Aires, Palestra, 1960), pp. 119/20.
} 
contradictorios y conflictivos - al progreso de la Razón y a la resolución de las crisis históricas. Para abreviar digamos que en la tradición occidental la función intelectual ha estado principalmente centrada en la universidad y en la inteligencia. Esta se encuentra representada por un conjunto de intelectuales autónomos en cuanto a formas particulares de institucionalización y dependencia orgánica con las estructuras de poder. Muchas veces esta intelectualidad ha reflejado los intereses de clases en ascenso con más altos niveles culturales, de grupos educados migratorios y de sectores minoritarios culturalmente diferenciados. Cualquiera que sean estos desajustes estructurales, ellos permiten una mayor perspectiva y conciencia de la realidad, a la que por la fuerza de su situación asumen de un modo crítico.

El problema consiste aquí, por lo tanto, en examinar las relaciones de diverso género (complementariedad, convergencia, divergencia, antagonismo) que establecen entre sí estos dos agentes que comparten la responsabilidad principal de la función intelectual en épocas y procesos de cambio histórico ${ }^{30}$. Se trata en primer lugar de enmarcarlas en el contexto de estructuras sociales identificadas de un modo tal que puedan ser reconocidas concretamente en sus conexiones fundamentales con la inteligencia. Cabe también no perder de vista lo que tienen en común y lo que los distingue del orden social vigente, así como las circunstancias sociales que los atraen y separan de él.

Medina Echavarría mostró una particular preocupación por este problema señalando que sería trágico que la universidad llegara a una situación de divorcio profundo con la intelectualidad independiente y crítica de su tiempo. Y esto porque entendía que a ella también le alcanzaba lo que en uno de sus primeros trabajos denominó "la responsabilidad de la inteligencia".

Si la universidad ha tendido a ser la institucionalización de la inteligencia, ha sido porque en ella radica la responsabilidad de asegurar la continuidad generacional del proceso de racionalización. Esto es, la transmisión de una generación a otra del principio animador de la inteligencia en cuanto reflexión de la sociedad sobre sí misma, de una sociedad que se autoescruta y que se construye y desarrolla mediante la acción humana.

De ahí la importancia trascendental que Medina atribuía a este tema sobre el que volvió una y otra vez a lo largo de toda su vida intelectual. Le preocupaba particularmente el problema de la posibilidad de "la cristalización de la cultura", o sea de una cultura que ha agotado todas sus "posibilidades de desarrollo porque éstas ya están dadas en sus supuestos fundamentales. Por tanto el movimiento y el despliegue subsisten, pero dentro de ámbitos ya conocidos en su conjunto" (p. 7). Cuando se llega a este punto existe una pérdida de la visión unitaria del mundo y de su dinamismo transformador. Y lo que acaso sea uno de sus signos más expresivos es la "atonía filosófica", esto es, la ausencia de una reflexión profunda que relaciona las bases y principios que fundamentan el presente histórico con las posibilidades que lo trascienden.

La conexión entre movimiento intelectual y universidad creativa, uno de los fundamentos principales del desarrollo del pensamiento occidental, no ha sido siempre positiva porque ella no tiene un sentido unívoco. En general, los movimientos intelectuales han fructificado en fases de fractura histórica (la disolución del mundo feudal, la emergencia de la civilización industrial), y en "situaciones de frontera cultural" (la influencia musulmana en España y el Mediterráneo y su gran florecimiento cultural). El

\footnotetext{
${ }^{30}$ Prefiero utilizar la idea de cambio histórico para referirme a las transformaciones irreversibles de la estructura de poder y de sus fuentes principales de legitimación ideológica y para distinguirlo así de otras clases de cambio social que pueden ser irrelevantes en este sentido.
} 
impulso inicial del movimiento fundacional de las universidades, que ocurrió precisamente en la cuenca mediterránea (Escuela de Traductores de Toledo, Nápoles, Toulouse, Bolonia, Montpellier, Salamanca), tuvo lugar en tales circunstancias históricas, es decir, cuando ambos factores trabajaron acoplados. Así la animación intelectual que en ellas se encarnaba procedía en gran parte del medio propicio y estimulante que las rodeaba.

Cabe agregar que estas coyunturas históricas propiciadoras presentaban características conflictuales que significaron el cuestionamiento del orden social hegemónico, lo que abrió un ancho cauce para el despliegue del disenso constructivo y crítico de los intelectuales. Así éste se gestaba naturalmente en respuesta a la progresiva pérdida de legitimidad de los sistemas históricos vigentes que entraban en procesos de rápida caducidad. De ahí que la función principal de la inteligencia haya sido su esfuerzo perenne para tejer el futuro con los "cabos sueltos" del pasado y del presente.

Como intérprete del mundo la inteligencia siente que su misión responde a la necesidad de encontrar salidas - siempre transitorias - a las contradictorias circunstancias que los sistemas históricos no pueden resolver por sus propios medios.

Estas circunstancias han puesto a la intelectualidad crítica en diversas relaciones con la universidad. Orgánicas y armoniosas, algunas veces, cuando el movimiento intelectual de la época ha encontrado su hogar en la universidad; en otros casos, de indiferencia y alejamiento cuando no de aguda confrontación. Al quedar aislada, la universidad ha perdido parte de su fuerza intelectual y ha tendido a rezagarse en el movimiento de la historia.

Para situar el problema que se intenta bosquejar, quizá se justifique partir de un truismo: la formación universitaria no ha sido nunca - y sólo por sí misma- un modo de ganarse la vida. Los motivos profundos por los cuales se estudia en la universidad consisten en una difícil amalgama de vocación con profesión en que ambas, sin estar disociadas en la realidad —como no lo están semánticamente-constituyen no obstante esferas relativamente independientes que se condicionan recíprocamente. Cuando la vocación es la que predomina, la función intelectual suele tener mayor gravitación. Por cierto que esto no significa en modo alguno que la universidad cuando cumple a cabalidad la función intelectual haya estado completamente disociada de los diversos "modus vivendi" existentes en una sociedad concreta. Al contrario, la educación universitaria como formación y capacitación profesional ha sido siempre un recurso productivo, como lo han señalado hasta la fatiga quienes se afilian a la corriente del "capital humano". Pero ocurre que la educación es eso y mucho más, y en su sentido general las funciones que cumple en una sociedad no pueden explicarse meramente por lo que signifique su aporte a la economía (como recurso productivo o bien de consumo) aunque en determinadas circunstancias históricas su inserción productiva revista una importancia fundamental, como ha sido evidentemente el caso en los ya dos largos siglos de vigencia de la civilización industrial ${ }^{31}$. El punto será tratado luego con más detenimiento.

Cuando se piensa más específicamente en las universidades como formando un complejo institucional más o menos estructurado e identificable, es necesario e importante interrogarse sobre su inserción orgánica en el orden social vigente. La clave de esta

\footnotetext{
${ }^{31}$ Entendemos aquí a la civilización industrial como un modo de organización de la vida social que se funda en el despliegue dominante de la racionalidad instrumental y en el predominio consiguiente de criterios técnico-científicos en la vida económica y social.
} 
conexión fundamental se encuentra —como dice Medina- en la peculiar relación entre un poder espiritual (la universidad) y un poder político (el Estado) ${ }^{32}$. Por lo tanto, lo que cuenta es la manera cómo la universidad se relaciona con la estructura de poder y la dinámica de las clases sociales y, en particular, con la formación de un sistema hegemónico, esto es, de un régimen político ideológicamente consensual que dispone de un margen amplio de legitimación social. Al mismo tiempo pero en otro sentido importa determinar su relación con los proyectos de cambio que se gestan en el seno de la sociedad civil y que pugnan por concretarse. La conexión de la universidad con los intelectuales se produce en ambos sentidos (de crítica o legitimación) pero su índole dependerá de cuál sea el tipo de relación de la universidad con el orden social que prevalezca.

Planteado así el problema, se puede agregar que la contribución de la universidad a la formación ideológica y el sentido de sus relaciones con las clases dominantes constituyen el pivote en torno al cual giran sus otras diversas funciones sociales y sus relaciones con la inteligencia.

La cuestión que aquí se intenta esbozar es histórica, ya que la inserción estructural del orden universitario ha variado con el tiempo, más que todo debido a las transformaciones de las relaciones de clases y de poder en la sociedad. Por eso mismo, se ha modificado el sentido de su función intelectual y sus relaciones con la inteligencia, no menos que con la estructura del Estado.

Si se atiende principalmente a las dos grandes dimensiones de relacionamiento de la universidad con la sociedad, que son la producción económica y la estructura de poder, es posible perfilar algunos tipos básicos de inserción histórica.

Nótese que cuando se habla de conexión económica se considera principalmente dos funciones de la universidad: la formación de cuadros profesionales superiores y la generación de conocimientos prácticos e innovaciones técnico-científicas para la producción económica.

En las relaciones de poder lo que cuenta esencialmente es la manera y el grado en que la universidad contribuye a la formación de la élite del poder ${ }^{33}$ y del sistema hegemónico. Entiéndase esto último en el sentido de consensualización ideológica (legitimación) del modo vigente de dominación. Esta contribución de la universidad puede ser ambigua y hasta contradictoria según las circunstancias concretas.

En una perspectiva histórica, se puede afirmar de la universidad que el modo de su inserción social ha sido la fuerza condicionante que más ha influido en su organización institucional, en las formas de saber y en los contenidos de conocimiento predominantes, así como en los arquetipos sociales de hombre de conocimiento y de profesional e

\footnotetext{
${ }^{32}$ La verdadera autonomía deriva del ámbito de libertad reconocida a la Universidad por el Estado por razón de que acepte la autoridad que ésta posee ya por sí misma. En este sentido perdura la autonomía espiritual de la Universidad aún allí donde se ha convertido en miembro uniforme de la actividad administrativa del Estado. Exige, por tanto, esa relación, por una parte que la Universidad posea ya de por sí, gracias a su prestigio social, la autoridad que opone a otras autoridades, incluida la suprema del Estado, y por otra que la política cultural del Estado tenga como principio fundamental de su doctrina y de su ejercicio la aceptación de la autoridad universitaria. La fascinante historia de la Universidad en los distintos países es sólo la historia de las distintas formas que ha tomado esa relación y de los delicados mecanismos de equilibrio que la han mantenido". (Ibidem, p. 154-55).

${ }^{33}$ Por su mayor vigencia actual prefiero utilizar el concepto de élite de poder no desvinculado del de clases dominantes. Esto no supone en modo alguno que asuma el rechazo de los fundamentos de clase de la élite de poder, siguiendo la tradición neomaquiavelista de Mosca y Pareto, con la que discrepo totalmente en este punto. En cambio, nuestra concepción de la élite de poder se encuentra más cerca de la de O. Wright Mills que relacione las clases sociales con la estructura corporativa de la sociedad industrial. No es ahora del caso elaborar más esto porque no tendría sentido y además porque ya lo he hecho en otros trabajos.
} 
intelectual universitario. Estos son los principales agentes sociales de su particular conexión con la sociedad global y con la inteligencia.

Siguiendo una línea a la vez taxonómica e interpretativa —abstrayendo acaso arbitrariamente- se pueden distinguir tres configuraciones típicas más salientes. La primera será denominada la universidad "disociada". La segunda, la universidad "aliada". Y la última, que intenta representar el momento actual de la universidad latinoamericana, la universidad "desvirtuada". Estas expresiones son sólo modos aproximativos -y acaso metafóricos- de referirse a características concretas e identificables de la inserción universitaria en la estructura de la sociedad ${ }^{34}$.

El primer tipo de inserción histórica es el de la universidad disociada y se caracteriza por su desconexión orgánica con el poder y las clases sociales y consiguientemente por su irrelevancia social en el sentido antedicho. Por eso resulta útil para esclarecer algunas de las cuestiones planteadas. Ella se encuentra bien configurada por el auge y la decadencia de la universidad medieval. Se trata de un largo proceso que abarca en sus orígenes, hacia fines del siglo $\mathrm{XI}$, al vasto movimiento europeo de fundación de universidades que con el correr del tiempo tienden a secularizarse. El mismo se extiende unos pocos siglos más tarde a la América hispana con la creación, en 1551, de las universidades imperiales de San Marcos de Lima y de México, que siguen la tradición abierta y populista de Salamanca (Steger). El período concluye con la decadencia progresiva de este tipo de universidad hacia el siglo XVIII.

La conexión social de la universidad en esta fase fue tal que pudo florecer intelectualmente desde sus comienzos debido precisamente a su disociación con la producción económica y a su relativa irrelevancia con respecto a la estructuración de las clases sociales y al ejercicio del poder. Todo esto le proporcionó un considerable margen de autonomía intelectual e institucional $y$, aunque parezca paradoja, una cierta representatividad social. En efecto, tanto en la sociedad feudal como en la sociedad renacentista burguesa que la sucede, la desconexión entre la producción económica y el poder, por un lado, y la universidad, por el otro, era prácticamente total. Poco relevante era ciertamente la formación de teólogos, filósofos y juristas para el funcionamiento del poder feudal o de las repúblicas urbanas, que estaba altamente personalizado. Tampoco era demasiado relevante para la economía el conocimiento que producía la universidad en una época histórica en que aún no había surgido la técnica científica moderna. Sería ocioso recordar que la forma predominante de producción era artesanal y se basaba en una tecnología empírica producto más que todo del ensayo y el error.

La inserción de la universidad medieval en la estructura de clases era difusa e inorgánica y esto porque ella correspondía más a un sistema de clases todavía en formación y menos a las clases dominantes de este período, que estaban ingresando a una fase de declinación histórica. Por lo tanto, la universidad no constituía un medio eficiente y reconocido de canalización de aspiraciones de movilidad social, tanto porque el prestigio y las recompensas económicas que recibía el intelectual universitario no eran elevados como porque el mundo de las ocupaciones productivas no se encontraba suficientemente estructurado ni el poder político estaba organizado burocráticamente. En otras palabras, no había modos para que la universidad participase en el poder, fuera éste económico o político.

\footnotetext{
${ }^{34}$ Este esquema clasificatorio procede, con variaciones nominales, de nuestro trabajo "Esbozo de una interpretación de la crisis actual de la universidad latinoamericana”, 1978 (mimeo, en publicación).
} 
En este sentido, la universidad secular fue quizá un orden institucional que se hallaba desfasado con relación a formaciones históricas donde todavía no era posible un despliegue pleno de sus potencialidades funcionales. De ahí, entre otras cosas, los frecuentes e intensos conflictos de los universitarios con el medio social circundante.

Como formaciones intelectuales las universidades medievales florecieron en medio de las luchas del poder político secular para afirmarse frente al poder religioso del Papado. Tanto como en otras circunstancias estas divisiones y luchas por el poder abrieron fisuras que resquebrajaron al orden medieval dominante las que fueron aprovechadas por los intelectuales críticos para promover un pensamiento utópico proclive al cambio. También en la estructura social de la época se pueden identificar elementos que contribuyeron en el mismo sentido de apertura social y política. Por ejemplo, es bien conocida la existencia de hombres educados disponibles, sin tierras ni títulos debido al sistema de mayorazgo, que buscaban "fortuna". Muchos de ellos eran portadores de un profundo resentimiento social fácilmente explicable dadas sus circunstancias. De ahí el tono predominantemente crítico y contestatario de muchos de los movimientos intelectuales, religiosos y seculares, de la época.

Quizá ningún testimonio literario sea tan elocuente de este desarraigo estructural de los universitarios como la picaresca española del Siglo de Oro con su desfile de bachilleres y licenciados, ambulantes, desocupados y mendicantes, que transitaban por las ciudades y caminos de España poniendo en evidencia con su precaria condición su falta de integración en una sociedad que aun carecía de posiciones ocupacionales apropiadas para ellos. También puede citarse a los goliardos, estudiantes migratorios que circulaban por las universidades de la Europa medieval ${ }^{35}$. Como se diría hoy en día eran típicos marginales que carecían de modos orgánicos de ganarse la vida y que apelaban a toda suerte de recursos - no siempre lícitos - para sobrevivir.

Aunque parezca paradojal, estas difíciles condiciones resultaron a la postre propicias para que se estableciese una armónica convergencia entre universidad e inteligencia asumiendo de consumo el poder intelectual de la sociedad. Desde fines del medioevo hasta bien entrado el renacimiento los más trascendentales debates y progresivos intelectuales se produjeron en la universidad o en relación estrecha con ella.

Tendría que producirse la revolucionaria conexión entre la ciencia empírica y la producción económica que dio origen a la revolución industrial para que se transforme la inserción social de la universidad ${ }^{36}$. Y esto ocurrió recién con el consiguiente advenimiento de la técnica científica y el florecimiento del capitalismo industrial desde el siglo XIX. Bajo estas nuevas condiciones se ingresa en la fase designada como de la universidad "aliada", que entró de lleno a una congruencia funcional y asociación relevante con la forma prevaleciente de producción económica y dominación política, esto es, con el capitalismo y la sociedad burguesa.

\footnotetext{
35 "Una manifestación especialmente significativa en el siglo XII fue la aparición de los goliardos. No constituían precisamente una clase ni su origen socioeconómico parece ser homogéneo. Es un agregado social formado por los que no participaban en las estructuras tradicionales porque huían o eran marginados de ella. Eran vagabundos que iban de ciudad en ciudad y que tenían en común hacer de la aventura una protesta contra el sistema establecido..." Ataliva Amengual, "Reflexiones sobre la fundación de la universidad", Estudios socia/es (Santiago de Chile), No. 16, 1978, p. 16.

${ }^{36}$ En rigor, este proceso había comenzado tiempo antes con los progresos de la racionalidad lógica', con la emergencia de un realismo todavía ingenuo, particularmente ostensible en las artes plásticas y que se anticipaba como el fundamento de lo que más tarde sería el pensamiento científico moderno. El avance del proceso racionalizador tuvo una variedad de concreciones significativas, siendo una de las mayores el descubrimiento de la contabilidad por partida doble en pleno medioevo que según Sombart ha sido el pilar fundamental del avenimiento del capitalismo.
} 
Como es bien sabido, este período histórico se caracterizó por grandes reformas en las universidades, muchas de las cuales habían quedado profundamente rezagadas con respecto al progreso intelectual de los dos siglos precedentes. En efecto, ya bien entrada la época moderna se había producido un divorcio creciente entre la universidad y el movimiento intelectual. Mientras aquella tendía a anquilosarse y a perder creatividad este último buscaba otras formas de institucionalización en cenáculos cortesanos, círculos intelectuales y, más tarde, en sociedades científicas.

Esta transición culminó en el siglo XIX cuando la ciencia experimental revolucionó la técnica productiva y con ello transformó fundamentalmente el modo de producción económica y no menos la inserción social de la universidad. El cambio comprendió a la propia organización interna de la universidad, y a los contingentes sociales que albergaba en su seno, así como a los nuevos campos de conocimiento que se expandieron y a las relaciones entre la diversificación de las profesiones universitarias y las fuerzas productivas que emergieron al impulso de la revolución industrial.

El pensamiento científico se tomó inseparable de la universidad, tanto en lo que se refiere a la investigación misma como - y de manera más exclusiva- a la formación de cuadros y a la transmisión generacional de la actitud y del método científico.

Las grandes reformas de la educación superior tuvieron su epicentro en las reformas universitarias alemana y francesa de comienzos del siglo XIX, que pusieron el acento en la conexión entre investigación y profesión, vinculando de ese modo a la universidad con la generación y transmisión de la técnica científica, por un lado, y con un mercado profesional, por el otro. Con ellas comienza el proceso de inserción orgánica en la producción económica y la estructura social, que está desvaneciéndose en el momento histórico presente ${ }^{37}$.

La vigorosa marcha del proceso racionalizador inherente a la civilización industrial se hizo sentir de muchas maneras y revirtió sobre la universidad misma transformando profundamente su sentido social. Desde ese momento la universidad quedó convertida en un factor decisivo del progreso técnico, no sólo por su contribución efectiva a la generación de innovaciones sino también por la influencia que ejerció en la preponderancia de la razón instrumental ${ }^{38}$.

Pero esta proyección social de la universidad quedaría confinada principalmente a la esfera productiva, que es donde la revolución del conocimiento técnico se desplegó más plenamente. Al respecto, Medina observó que el predominio de la razón técnica reduciría el campo de posibilidades de la racionalidad ético-política y con ello la contribución de la universidad a la función intelectual.

En efecto, la tajante separación liberal entre Estado y economía contribuyó a contener durante algún tiempo el avance del proceso racionalizador sobre el frente político e

\footnotetext{
37 "El concepto o idea de la universidad que prevalece aún entre nosotros al igual que las funciones del profesor universitario, tuvieron su origen en Alemania durante el siglo XIX... (Más tarde) Francia, Gran Bretaña y los Estados Unidos introdujeron una serie de reformas imitadas del ejemplo alemán”. J. Ben-David et al., La Universidad en Transformación (Barcelona, Seix Barral, 1966), p. 13-14. También H.A. Steger "Sobre la sociología de los sistemas universitarios del occidente de Europa y de Latinoamérica en los siglos XIX y XX”, en A. E. Solari (ed.) Poder y desarrollo. América Latina. Estudios sociológicos en homenaje a José Medina Echevarría. México, Fondo de Cultura Económica, 1977).

38 "A mediados del siglo XIX la universidad (alemana) tomó un aspecto más estrictamente académico, pero creó nuevas disciplinas y amplió sus horizontes intelectuales, de modo que casi toda la actividad cientifica importante de aquella época tuvo su origen dentro de la universidad". J. Ben-David. op. cit., (p. 17, subrayados agregados). Algo semejante puede afirmarse respecto del alcance de las reformas de Oxford y Cambridge después de 1850, y de la creación de las grandes ecoles francesas desde comienzos de ese siglo.
} 
ideológico, al menos en el área de las decisiones de mayor importancia pública, confinándolo a las materias técnico-científicas y económicas.

Es cierto que el Estado tendió a burocratizarse crecientemente pero no menos cierto es que la diferenciación entre poder político y administración pública se mantuvo claramente delineada. En este sentido, el siglo XIX ofreció un espectáculo paradojal: mientras la economía era cada vez más dominada por la vertiginosa expansión de la razón técnica, la política florecía como nunca antes debido al progreso de la democratización liberal y a la emergencia de nuevos sectores sociales participantes en el universo político de una ciudadanía continuamente ampliada. En otras palabras, se asistía a sendos procesos paralelos de politización democrática de la sociedad y el Estado, por un lado, y de tecnificación y racionalización empresarial de la economía por el otro. Con la configuración de la economía como un orden social autonomizado tenía su origen la tensión irreductible entre racionalidad formal y racionalidad material, que ya había señalado Max Weber y que fue una de las preocupaciones intelectuales dominantes de don José.

En este nuevo contexto histórico y al profesionalizarse la universidad se ligó cada vez más a la economía como productora de recursos humanos y de innovaciones técnicas. Al mismo tiempo se sometió a la política del Estado, a cuyo amparo pero bajo cuyas condiciones trató de definir su espacio de libertad académica.

La doctrina de la "neutralidad valorativa" del conocimiento social surgió precisamente en un momento en que la autonomía intelectual de la universidad era algo así como el premio que recibía por su prescindencia política y conformismo ideológico.

Donde fue más fuerte esta pretensión de ampliar los márgenes de libertad académica fue precisamente en Alemania cuando la dependencia económica y funcional de las universidades respecto del Estado era mayor. Después de la reforma decimonónica, las universidades alemanas se tornaron islas de privilegio, precisamente por la protección que les dispensó el Estado y por su estrecha conexión con las clases dominantes. En efecto, sólo ellas eran las que demandaban autonomía intelectual en la universidad, claro está que dentro del marco de una tácita aceptación del orden conservador prevaleciente.

De este modo la universidad renunciaba a ejercer sus responsabilidades de crítica de la sociedad y menos aún a la de contribuir a la orientación de los procesos de cambio histórico. No fue por azar que ninguna de las grandes utopías e ideologías decimonónicas se gestara en la universidad. Su relación con los intelectuales independientes había llegado a su punto más bajo.

La universidad misma se había convertido en una importante fuente de trabajo para las nuevas profesiones científicas. Conscientes de su ascendencia sobre el poder del Estado, quienes la ejercían buscaron definir su jurisdicción privativa renunciando para ello a su función intelectual.

Esta universidad no avanzó mucho más allá de una liberalización relativa del conocimiento, principalmente en el campo técnico-científico, pero dentro de una observancia respetuosa del orden social vigente. La prueba de esto se encuentra en que el marxismo no tuvo status académico reconocido ni tampoco las otras corrientes intelectuales y doctrinarias que cuestionaban el statu quo proponiendo alternativas de cambio radical. En cambio, las doctrinas reaccionarias, conservadoras y liberales encontraron en ella un ambiente acogedor y propicio. 
Empero, lo que estaba en juego en ese momento histórico era más que todo el despliegue y legitimación secular del conocimiento técnico, y eso pudo hacerse con todos los honores y las facilitaciones necesarias para desligarlo de las ataduras teológicas del pasado. La física, la química, la biología y otras ciencias naturales progresaron rápidamente en la universidad revolucionando continuamente el conocimiento práctico, mientras que al mismo tiempo ella podía presentar un frente ideológico estable y conformista que convalidaba el orden social que se estaba consolidando.

En suma, la universidad entró en una estrecha conexión orgánica con la economía y el poder, sea directamente mediante la creación científica y la innovación técnica, sea indirectamente mediante su aporte a la secularización y al proceso racionalizador de la vida social. Además, mantuvo una posición favorable al statu quo, expresando -aunque sin mucha convicción- la necesidad de obtener un conocimiento objetivo, neutro y prescindente en aquellas materias que se relacionaban más de cerca con el ejercicio del poder político y ja legitimidad de las jerarquías sociales e ideológicas reconocidas.

Ya fue indicado que el desarrollo del capitalismo industrial se basaba en el desenvolvimiento de dos procesos concurrentes a los que la universidad se vinculó de manera estrecha. Ellos fueron la tecnificación de base científica de la economía organizada en empresas productoras independientes y reguladas por el mercado, por un lado, y la ampliación de la politización del Estado, por el otro, que tenía lugar en sociedades que experimentaban intensos y efectivos procesos de "democratización fundamental" (Mannheim).

La idea de la politización del Estado se refiere primariamente a la progresiva ampliación de las bases sociales del poder político y a la emergencia de una arena política donde los problemas públicos se debaten con grados diversos de pluralismo y libertad por una ciudadanía en proceso de continua expansión. En rigor y aunque la participación política popular, en sus aspectos activos y pasivos, fuera restringida, lo cierto es que fue considerablemente más amplia que en cualquier momento del pasado anterior a las grandes transformaciones políticas liberales del siglo XIX.

Sin ánimo de abundar en esto, parece sin embargo oportuno recordar varios hechos que contribuyeron a la transformación de la sociedad política: la expansión y profundización de la concepción de ciudadanía, la significación de los procesos democráticos y electorales para la legitimación del poder político, la emergencia de una opinión pública políticamente ilustrada, una mayor apertura y tolerancia ideológica y, lo que es más próximo a nuestro análisis, un mayor refinamiento intelectual de la clase política. En efecto, la nueva clase política era relativamente más numerosa y poseía conexiones bastante más diversificadas con las clases y sectores dominantes. Además, todos estos cambios políticos ocurrían en sociedades con grados más elevados de movilidad social, movilización popular y organización política. Sin embargo, ya se advertía una definida tendencia a la creciente burocratización de la administración del Estado y de las grandes instituciones públicas y privadas, fueran estas religiosas, económicas, militares o civiles. Así, en los albores de una posible democracia liberal participacionista ya se perfilaba nítidamente la tendencia hacia el surgimiento de formas institucionales corporatistas y autoritarias, las que a la postre le restarían gran parte de su significación social concreta.

En el contexto de la sociedad burguesa emergente las profesiones universitarias crecieron muy aceleradamente así como se elevó su prestigio social y posición estructural. Además de su considerable influencia económica la universidad aportaba una 
reserva de candidatos potenciales para integrar la élite de poder; claro está que se incorporaban a ella sólo aquellos que pasaban con éxito a través de diversos y confiables modos de socialización y cooptación personal. Durante más de un siglo estas relaciones fueron estrechas y con vasos comunicantes abiertos que conectaban a la clase profesional con los círculos del poder político. De ahí que el acceso de los universitarios a los más altos escalones burocráticos y corporativos del poder fuera fácil y casi 'natural', pero no era así su incorporación al seno mismo del poder político del Estado. El ingreso a la élite de poder ya no reconocía como causa suficiente la posesión de un título universitario aunque éste pudiera ser un elemento necesario para ser considerado. En efecto, el plus que podía proyectar a un universitario a una posición de poder en el gobierno no constituía algo que la universidad proporcionaba por sí sola. Para ello eran fundamentales otros puntos de apoyo en las instituciones del Establishment y en la estructura de clases, reforzadas por un considerable particularismo familista.

El mundo universitario que se proyectó hasta bien avanzado el siglo XX presentaba además otras características que facilitaron su inserción en el modelo del estado liberal de ¡a fase capitalista industrial. En primer lugar, la unidad del mundo universitario. En cada país, las universidades eran relativamente homogéneas en su organización y en la calidad de su trabajo académico y formación profesional y las diferencias entre ellas eran más bien sectoriales que globales; había además una política universitaria nacional, sea derivada del Estado, sea de acuerdos establecidos libremente entre las universidades mismas a través de variados organismos interuniversitarios. Habida cuenta de las posibilidades de un país determinado sus universidades formaban un sistema relativamente orgánico y de parejo prestigio debido sobre todo a sus comunes raíces en la estructura de clases y de poder.

En segundo lugar, si bien las universidades de los países capitalistas industriales absorbieron rápidamente la investigación científica y ja generación de innovaciones técnicas, cuyos descubrimientos más significativos se produjeron en su seno, no fue así en cambio en lo que se refiere al debate sobre alternativas sociales y políticas, y menos aún ala generación de ideologías. Por jo general éstas vieron la luz fuera de jos claustros universitarios y quedaron por mucho tiempo desconectadas del trabajo académico, no obstante que muchas de ellas, subyaciendo a su parte doctrinaria, incluían profundos y novedosos aportes teóricos. Esta renovación intelectual fue la obra de intelectuales libres y críticos.

Quizá esto explique en parte la siempre difícil ubicación y vida de jas ciencias sociales en el contexto universitario, particularmente de aquellas cuya relación con las técnicas productivas es más remota. O sea de todas, menos de la economía clásica y neoclásica, y esto precisamente por su muy significativa contribución a la legitimación ideológica del capitalismo.

En tercer lugar, se sigue de lo anterior que había una necesidad funcional de preservar a las universidades de la politización para asegurar ja formación de élites cada vez más ilustradas y, sobre todo, de una intelligentzia orgánica identificada y al servicio del orden social y, consiguientemente, responsable del manejo de las complejidades del aparato del Estado y la economía. En estas condiciones el disenso abierto y frontal resultaba inaceptable. Parece no caber duda de que unas ciencias sociales críticas habrían constituido una amenaza intolerable para la armonía y continuidad del sistema de poder en que ja universidad estaba inmersa. Por eso permanecerían mucho tiempo al margen de jos claustros universitarios. 
Finalmente, queda aún por mencionar una cuestión no menos significativa que es la del delicado equilibrio de proporciones entre las masas del orden universitario y de la sociedad política. Apelando al simil de unas relaciones de mercado, es posible pensar que si la oferta de recursos humanos hubiera sido excesivamente desproporcionada a jas necesidades de jas fuerzas productivas y del sistema de dominación todo el sistema habría entrado en crisis. Ciertamente, muchas de las relaciones a que se alude no son cuantificables aunque las magnitudes no dejen de tener su importancia, como se verá más adelante al examinar situaciones sociales distintas - y hasta opuestascaracterizadas por la diversidad clasista y la saturación del mercado político como ocurrió en una fase posterior. Era por lo tanto necesario mantener el equilibrio de las proporciones recíprocas para no alterar la composición de jas clases dominantes, así como evitar la erosión del disenso crítico generalizado porque de estas condiciones dependía la existencia de una relación armónica y orgánica de una universidad aijada con el orden social dominante.

La universidad latinoamericana de este período mantuvo relaciones semejantes con el Estado, acaso con rasgos aún más evidentes. Fue en esencia una universidad profesionalizante dedicada principalmente a formar cuadros políticos y profesionales. En rigor, la "universidad de los abogados" (Steger) contribuyó tanto a la formación de una clase política ilustrada (los "doctores") como a formar profesionales competentes para un Estado cuyo orden jurídico y burocrático era cada vez más complejo y para una sociedad progresivamente "preformada por la ciencia" (como anotarl ${ }^{1}$ a Medina siguiendo la feliz conceptualización de Schelsky). Pero esto no significa en modo alguno que las universidades latinoamericanas se convirtieran en emporios del conocimiento científico y técnico. De hecho, no hicieron otra cosa que reproducir, casi siempre con considerable retraso y no sin distorsiones y menguas notables, el conocimiento técnico-científico que era corriente en los países capitalistas centrales.

Esta pasividad y relativa desconexión de la universidad latinoamericana con ¡a investigación científica acaso sea uno de los factores que coadyuvaron, desde los albores del siglo $\mathrm{XX}$, a la temprana emergencia de movimientos universitarios reformistas cuestionadores de ja alianza casi simbiótica de la universidad decimonónica con el Estado oligárquico. Baste señalar que los reclamos contenidos en los manifiestos reformistas, como el argentino de Córdoba de 1918, procuraban la renovación científica, por un lado, y la democratización del acceso a la universidad, por el otro. La moderna universidad de masas ya estaba prefigurada en los planteos estudiantiles de entonces, que recibieron una rápida y favorable acogida de diversos círculos intelectuales y políticos de la época. Particularmente importante fue el apoyo que je dispensó el gobierno radical, de sesgo populista, que implementó muchas de sus más importantes propuestas.

Con estas características de elitismo social y ¡imitado pluralismo ideológico ¡a universidad latinoamericana alcanzó su más alto grado de inserción orgánica, esto es, de relevancia y asociación armónica con el orden social capitalista liberal. Su crisis estructural de la universidad comenzará recién cuando este delicado equilibrio experimente imbalances y tensiones fundamentales, generadas tanto dentro mismo del orden universitario como por las transformaciones de su medio ambiente social ${ }^{39}$. Se

\footnotetext{
${ }^{39}$ Parece ser un hecho que desde sus orígenes la universidad hispano-americana se democratizó más rápidamente que la estructura social, dando así lugar a la emergencia de fuertes tensiones con el Estado y los poderes organizados. Medina ha señalado este punto: "Ahora bien, lo dudoso es que todo este proceso (de reforma) se deba a una adaptación de la universidad a una previa diferencia funcional en la sociedad misma, es decir, a un ajuste a las presiones rigurosamente articuladas de determinados grupos sociales, pues sólo en nuestros días toma conciencia de sí misma la transformación social de América Latina. Un examen atento nos mostraría la mayoría de estas reformas y creaciones como un resultado de impulsos corporativos o de propuestas de hombres públicos de amplia visión que se adelantaron en sus previsiones a la marcha misma de las mudanzas estructurales (de la sociedad)". (Ibidem, p. 161).
} 
ingresará así al llamado momento de la universidad desvirtuada, que entrañaría una nueva disociación orgánica y diferenciación funcional con el orden vigente. Estas circunstancias son bien distintas ciertamente de las del período fundacional de las universidades cuando la desconexión estructural era esencialmente diferente, ya que facilitaba una más armoniosa unidad del sistema universitario. Si de aquel momento parece lícito decir que la universidad se trataba de una "creación anticipada" porque correspondía más bien a un tiempo histórico que todavía no había madurado, ahora cabe preguntarse si la universidad que floreció desde el siglo pasado no se encuentra hoy en día en vías de una rápida transformación y dilución en un complejo e inédito ordenamiento.

En efecto, la quiebra de la unidad del mundo universitario parece ser total. Aunque esta fragmentación asuma características diversas, las nuevas configuraciones emergentes pueden ser en lo esencial reducidas a una dicotomía. Razonando estructuralmente se puede suponer que la nueva universidad de elite (distinta de la oligárquica clásica) tiene que ser ideológicamente conservadora e identificarse con el orden social vigente, mientras que jas de masas, que más propiamente representa sectores y clases en ascenso con fuertes aspiraciones sociales pero sin consolidación estructural, tendría por fuerza que ser progresista y acaso revolucionaria. En tanto que la primera está claramente implantada en la cúspide de la pirámide y estrechamente vinculada con la élite de poder, la otra representa fuerzas sociales en transformación, integradas mayoritariamente por nuevos sectores medios con poder que intentaban ganar reconocimiento social. Sus correspondientes en el campo de la inteligencia son los intelectuales orgánicos, en el primer caso, y los críticos, en el otro. En el pensamiento conservador de ¡os intelectuales orgánicos prevalece una postura pragmática más preocupada por jas armonías y equilibrios funcionales que aseguran la continuidad del sistema social. Es generalmente conciliador y ponderado. En cambio, el pensamiento de los intelectuales críticos es especulativo —rayano a veces en la utopía- y caracteriza a los sectores que procuran transformar la cultura dominante para cambiar el orden social. Su interés principal tiende a concentrarse en jas crisis y rupturas que siguen a las transformaciones estructurales y los conflictos sociales. A partir de ja reflexión crítica del presente en que se manifiesta su insatisfacción con respecto a alguna de sus características elaboran nuevas ideas y alternativas de cambio. Según las circunstancias históricas, unos u otros serán los llamados sea para atar los "cabos sueltos" del orden social vigente o para transformarlo en otro diferente.

Esta distinción ha cobrado una importancia creciente a medida que el capitalismo se ha convertido cada vez más en un modo de vida rígidamente controlado y racional. El principio de la racionalización está penetrando en todos los tejidos de la vida social. Acaso nada sea más indicativo de esta continua expansión de la racionalidad del cálculo económico y del principio de la eficiencia funcional que el "maridaje del desarrollo económico y una ciencia que cada vez interviene más y 'comprende' en estricto sentido menos" (p. 23).

\section{III}

La formación superior de los cuadros técnicos y profesionales superiores y de los miembros de la élite así como ja investigación técnico-científica se realizan ahora en un marco histórico-estructural profundamente modificado. La universidad ha perdido gran parte del control que anteriormente tuvo con el cuasi monopolio de estas esenciales funciones de las sociedades modernas. 
Para introducir este punto parecen necesarias algunas puntualizaciones aunque por fuerza tengan que ser esquemáticas. Entre los rasgos de las sociedades latinoamericanas actuales es posible señalar algunos factores que están condicionando jos procesos de cambio universitarios. No se ignora que éste es un contexto histórico estructural, complejo y variado, con muchos matices y diferencias significativas que aparecen en cuanto se desciende a los casos concretos. No obstante, acaso sean suficientes las siguientes indicaciones para situarlo aunque sea en un nivel necesariamente abstracto.

En primer lugar, la estructura económica. En un sentido, ésta ha experimentado procesos concurrentes de extrema complejización corporativa y técnica, por un lado, y de creciente diferenciación interna en términos de heterogeneidad estructural (fases tecnológicas, estructura ocupacional, escala operacional y productividad), por el otro. Se trata de la coexistencia de diversos órdenes de jerarquías técnicas y organizacionales a menudo yuxtapuestos pero no integrados orgánicamente. En otro sentido, se pueden señalar rápidamente la creciente transnacionalización de la economía doméstica e internacional, y la dependencia externa en materia de tecnología, mercados y financiamiento. Todo esto significa - para algunos intérpretes - una pérdida de relevancia de la nación como marco de referencia para la universidad.

En segundo lugar, cabe destacar el carácter concentrador de estos procesos, tanto en el plano económico como en el político y educativo. Hay una considerable interrelación entre ambas esferas y niveles de poder, quizá hoy mayor y más compleja que nunca antes, donde además concurre una creciente tendencia a la tecnocratización de las decisiones. Se ha diluido en gran medida ja separación entre Estado y economía —que tanta importancia tuvo en la historia universitaria del último siglo- aunque ahora se profesen doctrinas económicas neoliberales que sostienen justamente lo contrario, esto es, la presidencia y subsidiariedad del Estado. De un estado autoritario claro está que preconiza su no intervención en la dinámica del mercado cuando al mismo tiempo conforma la estructura de la sociedad a las necesidades de una economía capitalista oligopólica y de unas clases sociales que carecen de sustento propio en la sociedad civil.

Tercero, ja masificación de la universidad y la producción de profesionales en gran escala, que enfrenta una demanda ocupacional con tendencias estacionarias, ha dado lugar a una proletarización de las profesiones intelectuales que va en continuo aumento y constituye hoy en día un fenómeno de alcances universales ${ }^{40}$. Todo esto ocurre en sociedades semi-alfabetas, con grandes contingentes de la población que quedan al margen o no completan la educación elemental y que, consiguientemente, presentan bajos grados de escolaridad general de la fuerza de trabajo. En estos mismos países, sin

\footnotetext{
40 ."En los países industrializados con economía de mercado se viene observando desde hace varios años un empeoramiento de la situación de empleo para los trabajadores intelectuales... En Francia, por ejemplo, la falta de empleo para el personal dirigente ('cadres'), que antes de 1965 era insignificante, ha alcanzado desde 1974 proporciones preocupantes. En 1971, el número de demandas de empleo no satisfechas fue, para tal personal, de 14.000; en 1974, de 25.000, y en 1976, de 45.000". En el año comprendido entre "noviembre de 1975 y noviembre de 1976", la proporción de ingenieros, técnicos y personal dirigente sin empleo aumentó el 9,2\%, mientras que para el conjunto de los trabajadores la proporción fue del 2,0\%. También en los Estados Unidos y el Reino Unido se ha comprobado "un aumento mucho más rápido de tal proporción durante esta última década". En Canadá, en 1976, "se estimaba que el $25 \%$ de los graduados con títulos superiores seguían sin trabajo un semestre después de su graduación. En el mismo año, en Francia y Japón había una proporción de profesionales desempleados equivalentes a un tercio de una promoción anual de diplomados de ese nivel. En países subdesarrollados como las Filipinas, ¡a India y Sri Lanka "el elevado número de personas en posesión de un título académico sin empleo es uno de los rasgos característicos y preocupantes del mercado del empleo. En la India, mientras que el número de trabajadores inscritos en los servicios de empleo (como desempleados) aumentó entre 1957 y 1971 de 922.100 a 5.100.000, es decir, que se quintuplicó, el de trabajadores con título académico inscritos en dichos servicios aumentó de 32.300 a 334.000, es decir, más de diez veces; entre 1966 y 1971, el número de ingenieros inscritos aumentó de 23.0008 86.000, es decir, casi se cuadruplicó". El informe concluye esta revista diciendo así: "En resumen, en numerosos países es cada vez más difícil encontrar o conservar un empleo" (profesional). OIT, Condiciones de empleo y de trabajo de los trabajadores intelectuales, (Ginebra, 1977, p. 42-44).
} 
embargo, se anotan muy altas tasas de participación en la matrícula universitaria, tanto que en algunos sus tasas son más altas que en los países europeos. En ellos, la concentración de recursos y posibilidades educacionales puede ser calificada de formidable ${ }^{41}$.

Cuarto, jos procesos anteriores han conducido a ja saturación de los mercados de las profesiones universitarias y así a una creciente diferenciación y jerarquización de las universidades nacionales, a la privatización creciente de ¡os estudios superiores de mayor prestigio y a la transferencia de la formación más especializada y de más alto nivel (postgrado), que es estratégica para el orden social vigente, a centros académicos extranjeros y a otros organismos cuasi universitarios (civiles y militares). En ellos funcionan algunos de los más eficaces mecanismos de selección ideológica y de cooptación para jas posiciones de élite. Por lo tanto, se observa una creciente elitización de un pequeño sector universitario de cúpula, que tiende a autonomizarse encapsulándose respecto del resto del conjunto universitario, y a una devaluación paralela de los estudios superiores para las masas con una degradación evidente de su calidad formativa e ingresos y de su importancia funcional y prestigio social. Todo esto ocurre en momentos en que se está registrando una considerable ampliación de la base social de reclutamiento de los estudiantes de nivel superior. Nuevos sectores medios y capas altas de la clase obrera están logrando acceso a una estructura educativa elitista que sólo muy limitadamente se democratiza; porque una parte considerable de la expansión de la matrícula proviene de la mayor participación femenina y demás miembros de las familias de las capas más altas.

Finalmente, los procesos de concentración, jerarquización y tecnocratización del poder Estado, que en no pocos países de la región latinoamericana se ha tornado crecientemente autoritario, han estrechado los márgenes de libertad intelectual y la posibilidad de expresión del disenso crítico en las universidades. Al mismo tiempo, la distancia en aumento entre la cúspide y la base del sistema universitario acarrea tensiones entre los beneficiarios de la meritocratización elitista y jos amplios sectores medios y de clase obrera representados en las universidades de masas. Esto constituye una contradicción que abre paso a ja universidad "militante" (Medina), opuesta al gobierno y al régimen imperante cuando no al mismo sistema capitalista ${ }^{42}$. Las universidades más

\footnotetext{
41 "El crecimiento de la matrícula educacional por niveles en el período 1960-1975 (en América Latina) ha sido considerable en su conjunto, mostrando sin embargo marcadas diferencias cuando se contrastan los niveles educacionales uno con otro. En efecto, mientras la matrícula primaria se duplicó en ese período, la secundaria creció 5 veces y la de enseñanza superior más de 6 veces". Esta disparidad ha mostrado tendencias a acentuarse como lo revela la dinámica reciente del sistema en "el hecho de que en el último de los tres quinquenios considerados (1970-1975) el crecimiento anual de la matrícula primaria se enlenteció descendiendo al 3,9\%, mientras que las de secundaria y superior se elevaron al $12,6 \%$ y $16,8 \%$, respectivamente". Esta tendencia también se refleja en la composición de la matrícula total donde la participación del nivel primario desciende de $83 \%$ a $68 \%$, mientras que secundaria y superior acumuladas se elevan de un $14 \%$ a $28 \%$ de la matrícula global. Sin embargo, más grave que todo esto es el hecho de que para el conjunto de la región, una proporción superior a la mitad de la población en edad escolar no ingresa o deserta del sistema educacional antes de haber completado el período mínimo de educación formal que le asegure una alfabetización permanente, esto es, la posibilidad de utilizar activamente su potencial educativo en el trabajo y la vida cotidiana. Todo esto en un continente donde en estos momentos (1979) las universidades acogen a una población estudiantil de más de 5 millones que prosigue un crecimiento vertiginoso". Cf. CEPAL, El desarrollo económico y social y las relaciones externas de América Latina (E/CEPAL/1061, enero de 1979, Primera parte, III, 6).

42 "Si la "Universidad enclaustrada" ha sido siempre excepcional y hoy casi imposible "torre de marfil" tan sólo en el denuesto- su contraposición radical no lo es menos, porque acaba precisamente con la universidad misma. Frente a la "Universidad enclaustrada", la "Universidad militante" es la que se deja invadir sin tamiz alguno por los ruidos de la calle y reproduce en su seno, en exacto microcosmos, todos los conflictos y pasiones de su mundo. La tarea científica desaparece y sólo quedan los gritos sustituyendo a las razones. La apertura al mundo de la actividad universitaria — su única manera de influir sobre él - sólo cae, en consecuencia, en la forma de la "Universidad partícipe" es decir no militante ni enclaustrada. "Universidad partícipe"es aquella que enfrenta los problemas del día aceptándolos como tema riguroso de su consideración científica, para afirmar únicamente lo que desde esa perspectiva se puede decir... Nada de su tiempo puede serle ajeno, pero sólo en la medida que pueda situarlo a la distancia que exige su busca permanente de la verdad". (168/69).
} 
pobladas se convierten así en unas de las más importantes tribunas políticas (aunque no intelectuales) donde se manifiesta el disenso crítico a menudo vinculado con una actividad beligerante contra el gobierno y el orden social. En estas condiciones es común que la crítica sea reprimida. Para apreciar debidamente esto hay que tener en cuenta el peso político de la enorme masa de estudiantes universitarios que, en algunos países latinoamericanos, supera al número de obreros industriales.

La generalizada emergencia de estos conflictos universitarios está indicando la existencia de contradicciones estructurales que configuran una crisis, de una magnitud y profundidad anteriormente desconocida. La llamada cuestión universitaria parece preocupar a todo el mundo pero sus problemas no se resuelven.

Por un lado, jas universidades se profesionalizan cada vez más y son ampliamente utilizadas como un importante recurso político para contrarrestar fuertes tensiones sociales de grupos y sectores que por su ubicación estructural han ganado poder y cuyas aspiraciones profesionales y participatorias se expresan como vigorosas demandas educativas. Ellas sin embargo no pueden satisfacerse aceptablemente debido a la subutilización de capacidades y al subempleo y desempleo profesional. De aquí se deriva en gran parte la frustración y el resentimiento personal tanto como ja contestación abiertamente ideológica, que suele convertirse en ja negación de la crítica intelectual seria. Pero hay algo más. Una universidad profesionalizante que es al mismo tiempo una universidad militante resulta algo paradojal cuando con contradictorio. Y lo es aún más cuando en medio de estos avatares abandona su función intelectual, que no ejerce efectivamente desde el momento en que al renunciar a la investigación renuncia también al principal fundamento de la legitimidad del saber que ofrece y de la crítica social que construye sobre el mismo.

Por el otro lado, este desborde de ja masificación universitaria ha quebrado el equilibrio de proporciones a que se hizo referencia: la élite de poder no está ya en condiciones de absorber más que a una pequeña parte del considerable flujo de profesionales universitarios, sea en las posiciones de gobierno, sea en las empresas del sector moderno de la economía. Y en la competencia triunfan los graduados de las universidades de élite porque son considerados más capaces y confiables. La meritocratización de una sociedad tecnocrática tiene por fuerza que ser limitada porque de otro modo no podría conservar la consistencia de sus estrategias y políticas. Por eso> se desconfía de aquellos que proceden de universidades de mala calidad académica y más que todo cuando en ellas predomina el disenso crítico. Por eso también prefieren refugiarse en los más seguros y controlables resortes de cooptación social que han estado organizando en jos últimos años y que ahora tienden a institucionalizarse separadamente en las universidades élite y a recuperar su homogeneidad ideológica. Este proceso de diferenciación intrauniversitaria corresponde a un proceso de jerarquización equivalente de jas clases sociales de ja sociedad en su conjunto.

En esta situación se apela generalmente a una de dos alternativas -o a ambas complementariamente- que tienden a la elitización del sistema universitario. La primera consiste en la ruptura de hecho de la unidad y hornogeneidad del orden universitario, jo que se traduce en su elitización parcial y estratificación interna, jerarquizando en unas pocas instituciones académicas aquellos estudios superiores que responden a las necesidades profesionales y políticas del régimen vigente y masificando al resto para confinarlo a estudios de segundo orden, esto es, que no superan el nivel de un postsecundario profesional. Este subconjunto que adquiere características plenamente profesionalizantes, opera además como un mecanismo amortiguador que absorbe 
presiones sociales de masas y apunta hacia un mercado profesional en que abundan las demandas para ocupaciones de nivel medio. La segunda alternativa se propone elitizar y jibarizar a todo el conjunto universitario mediante el pago de elevadas matrículas y ja imposición de otros requisitos de selección discriminatorios para el acceso a la universidad de los sectores no elitarios. Lo demás lo harán los vínculos familísticos y otras relaciones particularistas, además de algunos severos controles de lealtad al orden social existente. O sea que la posibilidad de una meritocracia profesada es contrarrestada por una ascripción actuada que rige en el acceso a las posiciones elitarias. En cualquier caso, un monto considerable de coerción será imprescindible para el control de las situaciones de tensión que siguen a la imposición de cualquiera de estas alternativas de reestructuración universitaria.

Una de las secuelas posibles es la reducción del debate intelectual y del pluralismo ideológico en la universidad, fórmula bastante común en jos regimenes autoritarios. Con la represión se trata de denegar el disenso y de contrarrestar las tendencias al desarrollo de ideas y actitudes críticas del statu quo. Pero esto no resuelve ja cuestión de fondo, que tiene principalmente que ver con la falta de correlación entre la universidad en general y jos sectores de clase que controlan los diversos órganos corporativos del poder social y político. Así, lo que se intenta es esconder el problema y procurar que las tensiones se tornen latentes y se reabsorban por otros medios.

De cualquier manera que sea, esta universidad tiende a disociarse profundamente de los intelectuales libres porque su predicamento social termina por agotarse. Al abandonar su responsabilidad intelectual la universidad para jas masas tiene que optar entre un profesionalismo ramplón y una militancia radical más de una vez gobernada por el inmediatismo político con la consiguiente y rápida disminución de su reconocimiento social como fuente confiable de saber y poder intelectual.

\section{IV}

Pero no se trata sólo de la confiabilidad del conocimiento científico sino de algo más vital para el destino de la vida social. En efecto lo que está en cuestión es nada menos que la capacidad de orientar y tomar decisiones sobre lo que está sucediendo para buscar salidas a las situaciones críticas. La disposición de la sociedad para reflexionar sobre sí misma, de cuestionar para identificar sus problemas más agudos y, más aún, para generar las ideas y fuerzas necesarias que proyecten nuestro presente hacia el futuro es lo que parece estar desvaneciéndose ante nuestros ojos ${ }^{43}$.

Con esto estamos alcanzando al meollo de las preocupaciones prospectivas de Medina. Siguiendo a otros pensadores señalaba que "la pérdida de toda imagen del futuro (sea acaso) el signo más grave de la denominada crisis de Occidente". Concluía esta reflexión citando una frase sobrecogedora sobre el 'tema del tiempo' que se puede trasladar a la filosofía de la historia: "Entre la microscópica reducción del momento del

\footnotetext{
${ }^{43}$ Una de las cuestiones fundamentales de la filosofía de la historia es la relativa a los grados de autonomía de los hombres como agentes históricos. Para algunos — que siguen tradiciones de pensamiento muy antiguas - la historia es producto del destino y creen por lo tanto que los hombres están atrapados por las circunstancias. Otros, en cambio, sostienen que los acontecimientos no son inexorables, sino que son susceptibles de transformación por las deliberadas decisiones de círculos identificables de hombres de poder que de diversas maneras dirigen u orientan la marcha de la sociedad, claro está que con las naturales limitaciones debidas a la imprevisibilidad actual de. algunos factores históricos. El papel de los intelectuales difiere en una u otra alternativa. De impasividad y neutralidad cuando la historia es destino, de racionalización y búsqueda de alternativas cuando ella es concebida como realización humana. De cualquier modo, nasa es ciertamente más conservador que la idea de un destino implícito porque muchos de los que profesan tratan en realidad de disimular el poder determinante de que disponen. Cf. O. WRIGHT MILLS, op. cit., pp. 17/46.
} 
ahora y la macroscópica dilatación del universo sin fin está un inmenso vacío. Este vacío señala el lugar donde el presente se tragó pasado y futuro" (p. 72/73).

Esta metáfora del vacío le llevó a afirmar la necesidad de "la esperanza como principio", o sea como un modo de superar la "fijación en el presente", que es esclerosamiento cuando no parálisis suicida. A la irresponsabilidad ética del científico opuso la "responsabilidad de la inteligencia" que se ejerce como un permanente "compromiso con jas alternativas de salida" 44 . "El mayor problema del hombre actual es el de vivir con esperanza en un mundo donde esa expectativa no puede cristalizar ya en ninguna Utopía". Sin embargo, cualquier salida auténtica deberá por fuerza contener un futuro de esperanza. Ella es todavía posible y depende de ja imaginación creadora y de ja crítica de la razón sobre sí misma, que son las propiedades esenciales de la inteligencia.

Algunas preguntas inquietantes sobre la universidad y la vida intelectual sugiere este cuadro. Concuerdan con las cuestiones más generales que Medina Echavarría se formulaba y que conviene recordar por su pertinencia para estas reflexiones: "¿Constituye la Universidad en los días que corren el "principio promotor de la historia" en la América Latina? ¿Es el lugar en que se despliega "la más alta conciencia" en nuestra época? ¿Ofrece, en suma, con toda plenitud su poder espiritual?” (p. 169).

En un sentido más concreto parecen legítimas las siguientes cuestiones. ¿Cuánto pluralismo ideológico en ja universidad de masas puede tolerar un orden social elitista con perfiles autoritarios y tecnocráticos? ¿Qué relación podrá tener la universidad profesionalizante con la inteligencia independiente? ¿Qué otras instituciones y medios sociales podrán cumplir la vital función intelectual de vincular La transmisión generacional con la crítica del presente para diseñar el perfil del futuro? ¿Podrá ser concebible que el conocimiento técnico-científico con su gran potencial conservador y transformador pueda ser generado en organizaciones académicas donde impere el pluralismo ideológico y exista consecuentemente la posibilidad de disenso crítico?

${ }^{44}$ Cf. Responsabilidad de la inteligencia, p. 20/21. 